\title{
AN EVALUATION OF ENVIRONMENTAL AND CULTURAL FACTORS AFFECTING UNDER-FIVE MORTALITY IN KEBBI STATE, NIGERIA
}

\author{
Azaki J.B.*, Mundi R. and Dakyes S.P. \\ Department of Geography and Environmental Management, University of Abuja, Nigeria \\ *Corresponding E-mail: azakijephtah@gmail.com
}

Cite this article:

Azaki J.B., Mundi R., Dakyes S.P. (2021), An Evaluation of Environmental and Cultural Factors Affecting Under-Five Mortality in Kebbi State, Nigeria. African Journal of Environment and Natural Science Research 4(3), 71-92. DOI: 10.52589/AJENSROKF4QT0W

\section{Manuscript History}

Received: 8 June 2021

Accepted: 3 July 2021

Published: 3 Aug 2021

Copyright $(\odot 2020$ The Author(s). This is an Open Access article distributed under the terms of Creative Commons AttributionNonCommercial-NoDerivatives 4.0 International (CC BY-NC-ND 4.0 ), which permits anyone to share, use, reproduce and redistribute in any medium, provided the original author and source are credited.
ABSTRACT: Over the years, Nigeria at all levels of government has formulated and implemented health policies and programmes to reduce under-five mortality; and despite that, it is still among SubSaharan Africa countries with high under-five mortality rate. This study aimed at evaluating environmental and cultural factors affecting under-five mortality in Kebbi State, Nigeria. Multi-stage sampling technique was used to sample respondents. Structured questionnaires were administered to 625 women aged 15-49 years and 603 were retrieved, giving the response rate of $96.5 \%$. Descriptive statistics such as frequencies and percentages were employed to analyse the characteristics of the respondents and distribution of under-five mortality experienced by women based on the environmental and cultural factors. Logistic regression analysis was applied to determine the environmental and cultural factors affecting under-five mortality in the study area. The results of the Logistic regression analysis revealed that at $P$-value $<0.05$, source of water, frequency of washing water container, water treatment, method of disposing waste water, type of toilet, shared toilet, frequency of washing toilet, method of disposing child's stool, type of cooling appliance, number of persons per room, use of mosquito net, refuse disposal method and type of cooking fuel were found to be the environmental factors significantly affecting under-five mortality; while ethnicity, religion, practice of food taboo, belief in traditional medicine, belief about disease causation, mother's autonomy on child's health and family's decision on child's health were found to be the cultural factors significantly affecting under-five mortality in the study area. The study therefore concluded that environmental and cultural factors affect under-five mortality in Kebbi state. To reduce under-five mortality rate, it was recommended that government at all levels should step up efforts in providing adequate infrastructure for public use. Government and cultural organizations should mount advocacy programmes aimed at improving women's participation in child's health decision-making in the family.

KEYWORDS: Environmental Factors, Cultural Factors, Under-five Mortality, Kebbi State, Nigeria 


\section{INTRODUCTION}

Under-five mortality rate globally dropped from 90 deaths per 1,000 live births in 1990 to 48 deaths per 1,000 live births in 2012 (UN, 2013). Similarly, under-five mortality which was estimated to be 12.6 million in 1990 reduced to 5.3 million in 2018 (WHO, 2019). However, despite the global progress in under-five mortality reduction over the years, it has not been even at regional levels. Childhood mortality estimates by regions revealed that industrialized nations have the lowest. For instance, in 2015, Sub-Saharan Africa recorded $85 \%$ child mortality, being the highest, Oceanic (51\%), South Asia (33\%), South East Asia (27\%), North America (24\%), Western Asia 23\%, Latin America and the Caribbean 17\% and Eastern Asia 11\% (UNDP and UNRISC, 2017). Sub- Saharan Africa under-five mortality has been reported to be 10 -fold of the industrialized countries, carrying about half of the world's under-five deaths in 2015 (United Nations, 2015). Estimates of percentage reduction change of childhood mortality in Sub-Saharan Africa was 52\% which was lower than that of Eastern Asia (78\%), Latin America (69\%) and North America (67\%) (UNDP and UNRISC, 2017). In 2018, 1 in 13 children in Sub-Saharan Africa die before their fifth birthday, which is 15 times higher than the risk a child faces in Europe, where just 1 in 196 children aged less than five die (WHO, 2019).

Progress in under-five mortality reduction has been witnessed in Nigeria, but not significant enough when compared with some low-income and middle-income countries. For instance, between 1990 and 2000, Nigeria child mortality rate was estimated to be high, while countries like Bangladesh, Ethiopia, Liberia, Malawi, Nepal, United Republic of Tanzania have already lowered their rates by two-third (United Nations, 2013). The under-five mortality rate in Nigeria experienced a rise from 128 deaths per 1,000 live births in 2013 to 132 deaths per 1,000 live births in 2018 ((NPC and ICF International, 2019). Surprisingly, Nigeria and India in 2018 alone were reported to have accounted for about a third of children's deaths in the world; placing Nigeria among countries with the highest under-five mortality (World Health Organization, 2019). Reduction in under-five mortality rates in Nigeria has not even among the regions. For instance, Multiple Indicator Cluster Survey (MICS) 2017 showed that North West recorded the highest under-five mortality rate of 162 deaths per 1,000 live births, compared to North Central (103), North East (115), South East (67), South South (59) and South West (67). Similarly, Nigeria Demographic and Health Survey of 2018 reported under-five mortality rate of 187 deaths per 1,000 live births for North West Zone, which was higher than that of North Central (95), North East (134), South East (75), South South (73) and South West (62). Responding to unacceptable under-five mortality rate, various child health policies and programs have been launched in the country.

One of the initiatives is the National Child Health Policy of 2006 that provided long term direction for protecting and promoting the health of children. In 2007, to provide a framework to guide the federal, states and local government health planning process, National Strategic Health Development Plan was initiated. Within the framework of National Health Policy, National Reproductive Health Policy Strategy was created in 2001 to uphold Primary Health Care (PHC) as the key to health development in Nigeria. Other efforts included the National Health Policy which was launched in 2016 and $2^{\text {nd }}$ National Strategic Health Development Plan, 2017-2021. Health Financing Policy and Strategy, 2017 was also formulated to regulate financing of Health sector. The National Routine Immunization Strategic Plan (NRISP), 2013-2015 was initiated to combat childhood killer diseases. In 2012, Nigeria government launched Saving One Million Lives, which was aimed at achieving 
the Millennium Development Goal of reducing child mortality by two thirds before 2015 through expanding primary health services to women and children (United Nations, 2013). Other initiatives targeted at reducing child mortality included Exclusive breast-feeding, Helping Babies Breathe, Kangaroo Mother Care, Making Pregnancies Safer (MPS), Baby Friendly Hospital Initiative (BFHI), Nigeria's Midwives Service Scheme, Safe Motherhood initiative, Roll Back Malaria Initiative (RBM), elimination of Iodine Deficiency Disorder (YDD), Vitamin A Deficiency Control and Integrated management of Childhood Illness (IMCI).

Previous studies carried out have found environmental and cultural factors to be predictors of childhood mortality. Kandara et al. (2007) and Ayotunde et al. (2009) have found environmental factors to be influential in childhood mortality in Nigeria. Other studies included that of Edeme et al. (2015) and Adeolu et al. (2016) that found environmental factors to be determinants of under-five mortality in Nigeria. Also, household environmental factors such as source of water, toilet type, child's stool disposal method and use of bed net were found to be significantly related to child morbidity in Nigeria (Fasina, 2015). Adebowale et al (2017) and Jacob et al (2011) found housing materials to be associated with under-five mortality. On cultural factors, Yildiz (2018) observed that cultural practices of families are directly related to children's health, particularly on perception of illness, reaction to illness and therapy. Fayehun and Omololu (2011) found ethnic groups in Northern Nigeria to have the highest risk of child mortality. Bhalotra (2010) on effect of Religion on child health in India revealed Muslims exhibition of lower son preference, resulting to gender bias on childhood mortality. Although, these previous studies might have contributed to the understanding of environmental and cultural factors affecting under-five mortality in Nigeria and elsewhere; however, to the best of researchers' knowledge, they are still scanty in Kebbi state. Importantly, information from this present study would be useful in formulating health policies to reduce under-five mortality in Kebbi state and Nigeria at large.

\section{Study Area}

Kebbi State is located between latitude $10^{\circ} \mathrm{N}$ and $13^{0} \mathrm{~N}$ and Longitude $3^{0} \mathrm{E}$ and $6^{0} \mathrm{E}$. It lies at the extreme North West Corner of Nigeria. The state shares international borders with Benin Republic and Niger Republic in the North and West respectively. In Nigeria, Kebbi State shares borders with Niger State in the south and in the East with Sokoto and Zamfara States. It lies approximately at $700 \mathrm{~m}$ above sea level, enjoying tropical continental type of climate mainly controlled by two air masses, tropical maritime and tropical continental, blowing from Atlantic and Sahara Desert. The vegetation consists of partly that of northern guinea savannah and the Sudan savannah. In the northern guinea savannah, they are characterized by trees like, locust bean trees, shear butter trees and combretum species. In the northern part of the state, the Sudan savannah consist of open wood land with scattered trees such as acacia and dump palms. The state has a projected population of 4,440,000 in 2016 (National Bureau of Statistics and National Population Commission, 2010). The following tribes exist in the state: Hausas (dominant in Birnin-Kebbi, Argungu and Jega); Fulanis (dominant in Bunza, Dakin Gari and Gwandu); Kambari (dominant in Yauri and Ngaski); Dakarikari (dominant in Zuru, Danko and Sakaba) and Zabarmawa (dominant in Dandi and Illo) 


\section{Theoretical Framework}

Mosley and Chen analytical framework of 1984 was used as a guide for this study. The model postulated that all social and economic factors do not operate alone, but through what they referred to as proximate determinants to influence child survival or mortality. The major assumption of the model is that in an optimal setting, over $97 \%$ of new born infants can be expected to survive through the first five years of life. Reduction in this survival probably in any society is due to the operation of socio-cultural, economic, biological and environmental factors. The model further maintained that maternal factors that may influence child's survival are age, parity, child weight, birth interval, among others. Nutrient deficiency factors include calories intake, proteins, vitamins and minerals. Environmental factors include air pollution, food contamination, fingers and inmate objects, among others. Health seeking behavior factors are personal preventive measures, seeking medical attention, antenatal attendance and immunization, while injury could be accidental or intentional in a child. According to the model, these factors may cause morbidity; and if proper medical attention is not given, it may result to child mortality. This present study applied the model to determine the effect of environmental and cultural variables (independent variables) on under-five mortality (dependent variable) in Kebbi State respectively.

\section{METHODOLOGY}

\section{Research Design}

Cross- sectional survey research design was used in this study. The population of this study was all women aged 15-49 years. The data for the study consisted of both primary and secondary sources which included structured questionnaire, National Population Commission census data, textbooks, journals and internet materials. Multi-stage sampling technique was employed to sample respondents. In the first stage, two (2) Local Government Areas in the state were sampled. Birnin-Kebbi LGA was purposively selected based on its uniqueness as the state capital and also better disposed in terms of social amenities. To ensure that the remaining 20 LGAs were given equal chance of being included in the study, table of random numbers was used and Koko-Besse LGA was selected. In the second stage, for adequate representation and spatial distribution of sampling units, $30 \%$ of the wards were randomly selected in each of the two LGAs using table of random numbers. In the third stage, using the 2006 Census Locality and Enumeration Area list, 30\% settlements were selected in each of the wards using table of random numbers. The 141,326 total population of women aged 1549 years for the selected LGAs was estimated using 3.1\% Kebbi state population growth rate of 2006 census; and Yamane (1967) formula was then used to determine 625 sample size for the study. Yamane formula is widely used by researchers and has been adjudged to be simple, including its ability to determine sample size of both continuous and categorical survey variables (Isreal, 1992; Sarmam et al.; 2013, Islam, 2018). The sample size was therefore calculated as shown below: 


$$
\begin{aligned}
& \mathrm{n}=\mathrm{N} \\
& 1+N(e)^{2}
\end{aligned}
$$

Where:

$\mathrm{n}=$ Sample size required

$\mathrm{N}=$ the population size

$\mathrm{e}=$ Margin of error (4\%) at $95 \%$ confidence level.

$$
\begin{array}{r}
\mathrm{n=} \\
=\frac{141,326}{1+141,326(0.04)^{2}} \\
=\quad \frac{141,326}{141,327 \times 0.006} \\
\frac{141,326}{226.12}=625
\end{array}
$$

Out of 625 questionnaires administered to the women, 603 were retrieved and used, giving a response rate of $96.5 \%$. Summary of the number of selected wards, settlements, households and the sample size in each LGA are shown in Table 1.

Table 1: Number of Selected Households and Sample Size in Each of the Selected LGAs

\begin{tabular}{|l|c|c|c|c|}
\hline L.G.A & $\begin{array}{c}\text { No. of } \\
\text { Selected } \\
\text { wards }\end{array}$ & $\begin{array}{c}\text { No. of } \\
\text { selected } \\
\text { settlements }\end{array}$ & $\begin{array}{c}\text { No. of } \\
\text { Households in } \\
\text { Selected } \\
\text { settlements }\end{array}$ & Sample Size \\
\hline Birnin-Kebbi & 5 & 21 & 8,243 & 368 \\
\hline Koko/Besse & 4 & 12 & 3,874 & 257 \\
\hline Total & 9 & 33 & 12,117 & 625 \\
\hline
\end{tabular}

Source: Field Survey, 2018

\section{Data Analysis}

SPSS 23 environment was used to analyze the data. Descriptive statistics such as frequencies and percentages were employed to analyze the demographic and socio-economic characteristics of the respondents. Cross-tabulation, involving frequencies and percentages were used to analyse the under-five mortality experience based on the environmental and 
cultural factors. Logistic regression analysis was used to determine the environmental and cultural factors affecting under-five mortality in the study area, using $<0.05$ as the $p$-value.

\section{RESULTS AND DISCUSSION}

\section{Demographic and Socio-economic Characteristics of the Respondents}

Table 2 presents the descriptive analysis of the demographic and socio-economic characteristics of the respondents.

Table 2: Distribution of Demographic and Socio-economic Characteristics of the Respondents

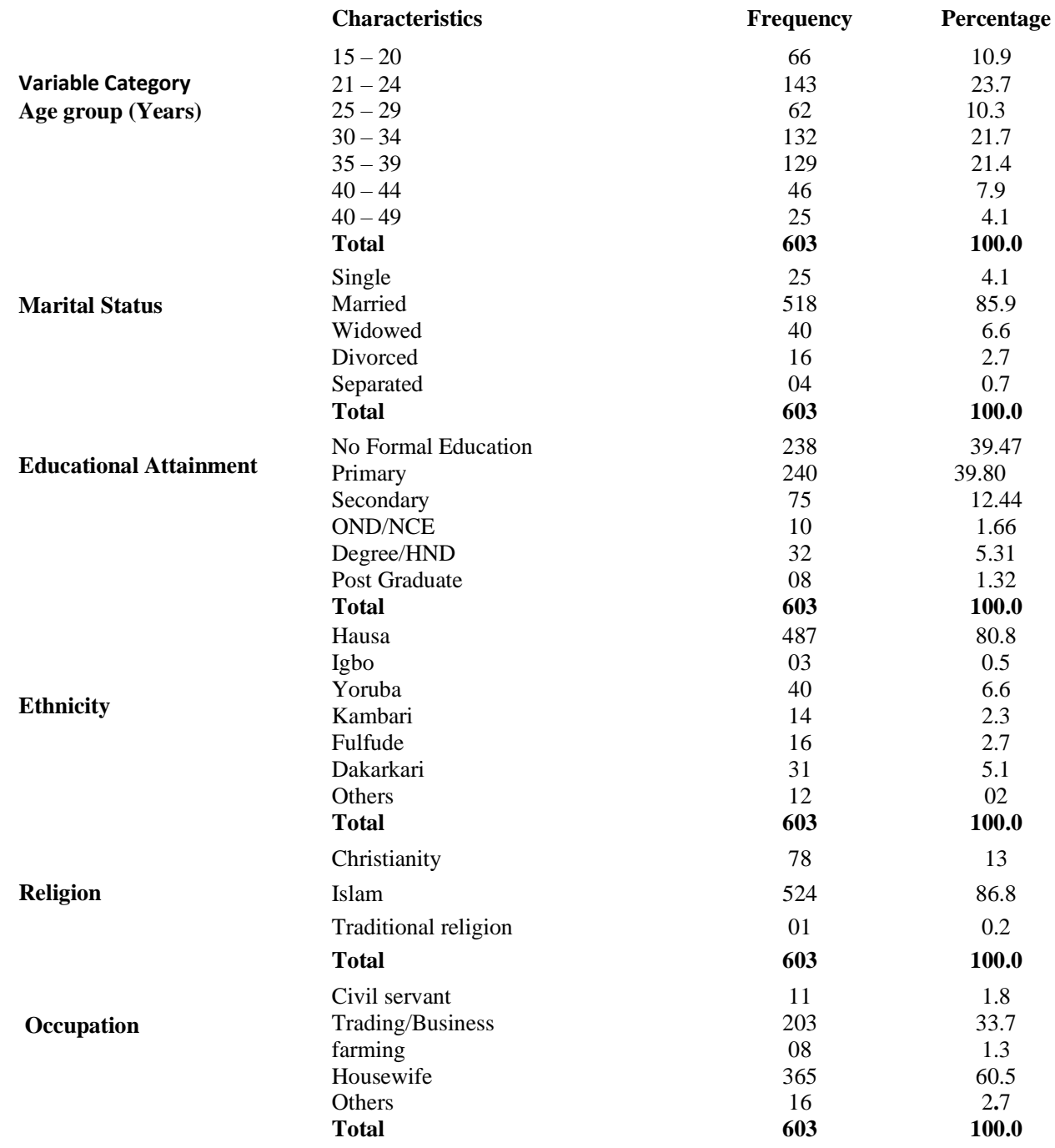


A total of 603 women aged 15-49 years were interviewed using structured questionnaires. Out of 603 respondents, $215(35.7 \%)$ of them indicated to have experienced under-five deaths within 5 years preceding this survey. The mean age of the women was 30 years, with majority of the respondents $(23.7 \%)$ in the age group 21-24 years, while the age group 45-49 had the least respondents of $4.1 \%$. The results further indicate that $85.9 \%$ of respondents were married, $4.1 \%$ of them single; while widows and divorcees were $6.6 \%$ and $2.7 \%$ respectively. The respondents with primary education constituted the highest respondents with $39.80 \%$, while those with post-graduate qualification were the least, constituting $1.33 \%$. Respondents that were Hausas constituted $80.8 \%$, being the majority and the least respondents $(0.5 \%)$ were Igbos. The respondents $(86.8 \%)$ that practice Islam were the majority, while Traditional religion worshipers were the least with $0.2 \%$. The results also show that $60.5 \%$ of the respondents were housewives and those that were into trading/businesses were $33.7 \%$. Civil servants and farmers constituted $1.8 \%$ and $1.3 \%$ respondents respectively, while $2.7 \%$ were into other occupations.

\section{Environmental Factors and Under-five Mortality Experience}

Table 3 shows that under-five mortality experienced by women that source water from river/stream was $28.4 \%$, while those that source water from tap experienced the least underfive mortality (3.7\%). Under-five mortality (66\%) was occurred among women that do not treat water, while $34 \%$ was experienced by the respondents that treat water. The results also revealed that women that store water in rubber drum/bucket/jerry can without cover experienced more under-five mortality $(49.8 \%)$, while low under-five mortality $(0.5 \%)$ occurred among women that use rubber drum/jerry can with cover. Under-five mortality $(42.8 \%)$ was recorded by women that wash water storage container weekly, with only $5.1 \%$ recorded by women that wash water container daily. The respondents that dispose waste water into open field experienced more under-five mortality $(58.2 \%)$, while the least $(5.6 \%)$ was experienced by women that use open drainage channel to dispose waste water. More under-five mortality $(37.2 \%)$ occurred among women that use open pit without cover as toilet, while those that use water system with cover experienced only $8.4 \%$ under-five mortality. The study further revealed that $62.3 \%$ under-five mortality was experienced by women that share toilet facility, while less under-five mortality $(37.7 \%)$ occurred among women that do not share toilet.

Women that wash toilet weekly experienced $36.7 \%$ under-five mortality, with only $16.7 \%$ under-five mortality experienced by women that wash toilet daily. Women that dispose child's stool at the backyard experienced the highest under-five mortality of $28.4 \%$, while those that flush child's stool with water experienced the least under-five mortality of $8.4 \%$. Under-five mortality (51.6\%) was experienced by women that dump refuse at the backyard, against $11.6 \%$ under-five mortality by women that dump refuse in the stream/ river.

The results in Table 3 also show that $35.8 \%$ under-five mortality occurred among women that live in single room, while those that live in story building recorded the least under-five mortality of $4.7 \%$. Women that live in thatch roofed house experienced the highest under-five mortality $(41 \%)$, while those that live in stone coated sheet house experienced the least under-five mortality (8\%). Under-five mortality (37.2\%) occurred among women that live in earth/mud floor house, while those that live in a house floored with other materials recorded the least under-five mortality (9.4). Under-five mortality (10.3\%) was experienced by women 
African Journal of Environment and Natural Science Research

ISSN: 2689-9434

Volume 4, Issue 3, 2021 (pp. 71-92)

www.abjournals.org

that live in a house with one window, while the highest under-five mortality $(40.9 \%)$ occurred among women that live in a house without window.

Table 3: Distribution of Under-Five Mortality by Environmental Factors

Ever lost under-five

\begin{tabular}{|c|c|c|c|c|c|}
\hline \multirow{2}{*}{ Variables } & \multicolumn{2}{|c|}{ Yes } & \multicolumn{3}{|c|}{ No } \\
\hline & No & $\%$ & No & $\%$ & Total $(\%)$ \\
\hline \multicolumn{6}{|l|}{ Source of water } \\
\hline Uncovered well & 56 & 26 & 122 & 31.4 & $178(29.5)$ \\
\hline Covered well & 16 & 7.4 & 21 & 5.4 & $37(6.1)$ \\
\hline Manual/Motorized borehole & 20 & 9.3 & 03 & 0.8 & $23(3.8)$ \\
\hline Water vendors & 27 & 12.6 & 100 & 25.8 & $127(21.1)$ \\
\hline River/stream & 61 & 28.4 & 120 & 30.9 & $181(30)$ \\
\hline Tap & 08 & 3.7 & 02 & 0.5 & $10(1.7)$ \\
\hline Others & 27 & 12.6 & 20 & 5.2 & $47(7.8)$ \\
\hline Total & 215 & 100 & 388 & 100 & $603(100)$ \\
\hline \multicolumn{6}{|l|}{ Water treatment practice } \\
\hline Yes & 73 & 34 & 246 & 63.4 & $319(52.9)$ \\
\hline No & 142 & 66 & 142 & 36.6 & $284(47.1)$ \\
\hline Total & 215 & 100 & 388 & 100 & $603(100)$ \\
\hline \multicolumn{6}{|c|}{ Type of water storage container } \\
\hline Rubber drums without cover & 103 & 47.9 & 128 & 33 & $235(38.9)$ \\
\hline Clay pot & 65 & 30.2 & 97 & 25 & $162(26.9)$ \\
\hline Metal tank & 12 & 5.9 & 36 & 9.3 & $51(8.5)$ \\
\hline Rubber drums with cover & 16 & 7.1 & 76 & 19.6 & $98(16.3)$ \\
\hline Rubber tank & 09 & 4.2 & 20 & 5.2 & $21(3.5)$ \\
\hline Others & 05 & 4.7 & 31 & 7.9 & $36(5.9)$ \\
\hline Total & 215 & 100 & 388 & 100 & $603(100)$ \\
\hline \multicolumn{6}{|c|}{ Frequency of washing water container } \\
\hline Daily & 11 & 5.1 & 80 & 20.6 & $91(15.1)$ \\
\hline Twice a week & 36 & 16.7 & 24 & 6.2 & $60(9.9)$ \\
\hline Weekly & 92 & 42.8 & 147 & 37.9 & $239(39.3)$ \\
\hline Twice a month & 16 & 7.4 & 67 & 17.3 & $83(13.8)$ \\
\hline Monthly & 60 & 28 & 70 & 18 & $130(21.6)$ \\
\hline Total & 215 & 100 & 338 & 100 & $603(100)$ \\
\hline \multicolumn{6}{|c|}{ Method of waste water disposal } \\
\hline Open drainage channel & 12 & 5.6 & 69 & 17.8 & $81(13.4)$ \\
\hline Infiltration pit & 13 & 06 & 50 & 12.4 & $63(10.4)$ \\
\hline Open field & 125 & 58.2 & 154 & 39.7 & $279(46.7)$ \\
\hline Simple pit & 29 & 13.5 & 63 & 16.2 & $92(15.3)$ \\
\hline Others & 36 & 16.7 & 52 & 13.4 & $88(14.6)$ \\
\hline Total & 215 & 100 & 388 & 100 & $603(100)$ \\
\hline \multicolumn{6}{|l|}{ Shared toilet } \\
\hline Yes & 134 & 62.3 & 79 & 20.4 & $213(35.3)$ \\
\hline No & 81 & 37.7 & 309 & 79.6 & $390(64.7)$ \\
\hline Total & 215 & 100 & 388 & 100 & $603(100)$ \\
\hline
\end{tabular}




\begin{tabular}{|c|c|c|c|c|c|}
\hline \multicolumn{6}{|l|}{ Type of toilet facility } \\
\hline Open pit without cover & 80 & 37.2 & 105 & 27.1 & $85(30.7)$ \\
\hline Open pit with cover & 25 & 11.6 & 63 & 16.2 & $88(14.6)$ \\
\hline Water system without cover & 38 & 17.7 & 61 & 15.7 & $99(16.4)$ \\
\hline Water system with cover & 18 & 8.4 & 84 & 21.4 & $102(16.9)$ \\
\hline Others & 54 & 25.1 & 75 & 19.3 & $129(21.4)$ \\
\hline Total & 215 & 100 & 388 & 100 & $603(100)$ \\
\hline \multicolumn{6}{|c|}{ Frequency of washing toilet } \\
\hline Daily & 35 & 16.3 & 81 & 20.9 & $116(19.2)$ \\
\hline Twice a week & 28 & 13 & 90 & 23.1 & $18(19.6)$ \\
\hline Weekly & 79 & 36.7 & 102 & 26.1 & $81(30)$ \\
\hline Monthly & 73 & 34 & 115 & 29.6 & $188(31.2)$ \\
\hline Total & 215 & 100 & 388 & 100 & $603(100)$ \\
\hline \multicolumn{6}{|c|}{ Method of child's stool disposal } \\
\hline Flush with water & 18 & 8.4 & 92 & 23.7 & $110(18.2)$ \\
\hline Pour at the backyard & 61 & 28.4 & 81 & 20.9 & $142(23.5)$ \\
\hline Cover with sand & 50 & 23.3 & 90 & 23.2 & $140(23.2)$ \\
\hline Pour in a pit latrine & 40 & 18.6 & 100 & 25.8 & $140(23.2)$ \\
\hline Others & 46 & 21.3 & 25 & 6.4 & $71(11.9)$ \\
\hline Total & 215 & 100 & 388 & 100 & $603(100)$ \\
\hline \multicolumn{6}{|c|}{ Method of dumping refuse } \\
\hline At the backyard & 111 & 51.6 & 131 & 33.8 & $242(40.1)$ \\
\hline Stream/River & 25 & 11.6 & 104 & 27 & $129(21.4)$ \\
\hline Community refuse pit & 49 & 22.8 & 124 & 32 & $173(28.7)$ \\
\hline Other & 30 & 14 & 29 & 7.2 & $59(9.8)$ \\
\hline Total & 215 & 100 & 388 & 100 & $603(100)$ \\
\hline \multicolumn{6}{|l|}{ Type of living house } \\
\hline Single room & 7 & 35.8 & 66 & 17 & $143(23.7)$ \\
\hline Room /Parlour & 63 & 29.3 & 31 & 8.0 & $94(15.6)$ \\
\hline Bungalow & 41 & 19 & 167 & 43 & $208(34.5)$ \\
\hline Duplex & 24 & 11.2 & 99 & 26 & $123(20.4)$ \\
\hline Story building & 10 & 4.7 & 25 & 6.0 & $35(5.8)$ \\
\hline Total & 215 & 100 & 388 & 100 & $603(100)$ \\
\hline \multicolumn{6}{|l|}{ Type of roofing materials } \\
\hline Stone coated sheet & 13 & 06 & 61 & 15.7 & $74(12.3)$ \\
\hline Thatched roofing & 88 & 41 & 93 & 24.0 & $181(30)$ \\
\hline Corrugated zinc sheet & 47 & 21.9 & 86 & 22.2 & $133(22.1)$ \\
\hline Asbestos sheet & 39 & 18.1 & 87 & 22.4 & $126(20.8)$ \\
\hline Others & 28 & 13 & 61 & 15.7 & $89(14.8)$ \\
\hline Total & 215 & 100 & 388 & 100 & $603(100)$ \\
\hline \multicolumn{6}{|l|}{ Type of floor } \\
\hline Earth /mud & 80 & 37.2 & 108 & 27.8 & $188(31.2)$ \\
\hline Gravel & 42 & 19.5 & 81 & 20.9 & $123(20.4)$ \\
\hline Cement & 48 & 22.3 & 100 & 25.2 & $148(24.8)$ \\
\hline Tiles & 25 & 11.6 & 48 & 12.4 & $73(12.1)$ \\
\hline Others & 20 & 9.4 & 51 & 13.1 & $71(11.8)$ \\
\hline Total & 215 & 100 & 388 & 100 & $603(100)$ \\
\hline 79 & & $\begin{array}{l}\text { Article } \\
\text { DOI U }\end{array}$ & $\begin{array}{l}\text { 2589/A } \\
\text { //doi.org }\end{array}$ & $\begin{array}{l}-\mathrm{OKF} 4 \mathrm{Q} \\
89 / \mathrm{AJE}\end{array}$ & $\begin{array}{l}\text { OW } \\
\text { R-OKF4QT0W }\end{array}$ \\
\hline
\end{tabular}


African Journal of Environment and Natural Science Research

ISSN: 2689-9434

Volume 4, Issue 3, 2021 (pp. 71-92)

www.abjournals.org

\begin{tabular}{llllll}
\hline No of windows per room & & & & & \\
1 & 88 & 40.9 & 144 & 37.1 & $232(38.5)$ \\
2 & 67 & 31.1 & 138 & 35.6 & $205(33.9)$ \\
3 & 38 & 17.7 & 70 & 18 & $108(17.9)$ \\
None & 22 & 10.3 & 36 & 9.3 & $58(9.7)$ \\
Total & $\mathbf{2 1 5}$ & $\mathbf{1 0 0}$ & $\mathbf{3 8 8}$ & $\mathbf{1 0 0}$ & $\mathbf{6 0 3}(\mathbf{1 0 0})$ \\
\hline
\end{tabular}

Number of persons per. Room

\begin{tabular}{|c|c|c|c|c|c|}
\hline $1-2$ & 39 & 18.1 & 110 & 28.3 & $149(24.7)$ \\
\hline $3-4$ & 26 & 12.2 & 81 & 20.9 & $107(17.7)$ \\
\hline $5-6$ & 56 & 26 & 99 & 25.5 & $155(25.8)$ \\
\hline 7 above & 94 & 43.7 & 98 & 25.2 & $192(31.8)$ \\
\hline Total & 215 & 100 & 388 & 100 & $603(100)$ \\
\hline \multicolumn{6}{|c|}{ Type of cooling appliance } \\
\hline Air Conditioner & 20 & 9.3 & 103 & 26.5 & $123(20.4)$ \\
\hline Table Fan & 55 & 25.6 & 104 & 26.8 & $159(26.4)$ \\
\hline Ceiling Fan & 60 & 28 & 92 & 23.8 & $152(25.2)$ \\
\hline None & 80 & 37.1 & 89 & 22.9 & $169(28)$ \\
\hline Total & 215 & 100 & 388 & 100 & 603(100) \\
\hline \multicolumn{6}{|c|}{ Use of mosquito net } \\
\hline Yes & 92 & 42.8 & 234 & 60.4 & $326(54.1)$ \\
\hline No & 123 & 57.2 & 154 & 39.6 & $277(45.9)$ \\
\hline Total & 215 & 100 & 388 & 100 & $603(100)$ \\
\hline \multicolumn{6}{|c|}{ Type of cooking fuel } \\
\hline Electricity & 07 & 3.3 & 51 & 13.1 & $58(9.6)$ \\
\hline Gas & 10 & 4.7 & 54 & 13.9 & $64(10.6)$ \\
\hline Kerosene & 11 & 5.1 & 57 & 14.7 & $68(11.3)$ \\
\hline Charcoal & 60 & 27.9 & 61 & 15.8 & $121(20.1)$ \\
\hline Wood & 71 & 33 & 91 & 23.5 & $162(26.9)$ \\
\hline Animal Dugs & 31 & 14.4 & 70 & 18 & $101(16.7)$ \\
\hline Others & 25 & 11.6 & 04 & 01 & $29(4.8)$ \\
\hline Total & 215 & 100 & 388 & 100 & 603(100) \\
\hline \multicolumn{6}{|c|}{ Type of animal domesticated } \\
\hline Dog & 35 & 16.3 & 71 & 18.3 & $106(17.6)$ \\
\hline Cat & 20 & 9.3 & 48 & 12.4 & $68(11.3)$ \\
\hline Cattle & 46 & 21.4 & 70 & 18 & $116(19.2)$ \\
\hline Sheep/Goat & 63 & 29.3 & 90 & 23.2 & $153(25.4)$ \\
\hline Birds & 25 & 11.6 & 60 & 15.5 & $85(14.1)$ \\
\hline None & 26 & 12.1 & 49 & 12.6 & $75(12.4)$ \\
\hline Total & 215 & 100 & 388 & 100 & $603(100)$ \\
\hline
\end{tabular}

Source: Field Survey, 2018

The results further showed that $43.7 \%$ under-five mortality occurred among women that sleep more than 7 in a room, with the least under-five mortality $(12.2 \%)$ experienced by women that sleep 3-4 in a room. The results further revealed that $37.1 \%$ under-five mortality occurred among women that do not use cooling appliance, with those using air conditioner 
experiencing the least under-five mortality of $9.3 \%$. The highest under-five mortality $(66 \%)$ occurred among women that do not use mosquito net, while those that use mosquito net experienced $34 \%$ under-five mortality. The results of the study also show that $33 \%$ of underfive deaths occurred among women that use wood as cooking fuel, while those that use electricity recorded the least under-five mortality of 3.3\%. Women that keep sheep/goat experienced $29.3 \%$ under-five deaths, against those that domesticate cat with the least underfive mortality of $9.3 \%$ (Table 3 )

\section{Cultural Factors and Under-Five Mortality Experience}

Table 4 reveals that Hausa ethnic group experienced 90.7\% under-five mortality, while the Igbo women experienced the least under-five mortality $(0.5 \%)$. The highest under-five mortality $(92.6 \%)$ was experienced by Muslim women, with respondents that practice traditional religion experiencing the least under-five mortality $(0.5 \%)$. Under-five mortality (78.6\%) occurred among women that practice food taboo, while the least under-five mortality (21.4\%) occurred among women that do not practice food taboo. In the same vein, under-five mortality $(72.6 \%)$ was experienced by women that belief in traditional medicine, while $27.4 \%$ under-five mortality occurred among women that do not belief in the traditional medicine.

Table 4: Distribution of Under-Five Mortality by Cultural Factors

Yes $\quad \frac{\text { Ever lost under five }}{\text { No }}$

\begin{tabular}{llllll}
\hline Variables & No & \% & No & \% & Total (\%) \\
\hline Ethnicity & & & & & \\
\hline Hausa & 195 & 90.7 & 292 & 75.3 & $487(80.8)$ \\
Igbo & 01 & 0.5 & 03 & 0.8 & $04(0.7)$ \\
Yoruba & 04 & 1.9 & 36 & 9.3 & $40(6.6)$ \\
Kambari & 02 & 0.8 & 12 & 3.1 & $14(2.4)$ \\
Fulfude & 05 & 2.3 & 11 & 2.8 & $16(2.7)$ \\
Dakarikari & 04 & 1.9 & 26 & 6.6 & $30(4.9)$ \\
Others & 04 & 1.9 & 08 & 2.1 & $12(1.9)$ \\
Total & $\mathbf{2 1 5}$ & $\mathbf{1 0 0}$ & $\mathbf{3 8 8}$ & $\mathbf{1 0 0}$ & $\mathbf{6 0 3}(\mathbf{1 0 0})$ \\
\hline Religion & & & & & \\
Christianity & 15 & 6.9 & 63 & 16.2 & $78(13)$ \\
Islam & 199 & 92.6 & 325 & 83.8 & $524(87)$ \\
Traditional religion & 01 & 0.5 & 0 & 0 & $0(0.0)$ \\
Total & $\mathbf{2 1 5}$ & $\mathbf{1 0 0}$ & $\mathbf{3 8 8}$ & 100 & $\mathbf{6 0 3}(\mathbf{1 0 0})$ \\
\hline Practice of food taboo & & & & \\
Yes & 169 & 78.6 & 140 & 36.1 & $309(51.2)$ \\
No & 46 & 21.4 & 248 & 63.9 & $294(48.8)$ \\
Total & $\mathbf{2 1 5}$ & $\mathbf{1 0 0}$ & $\mathbf{3 8 8}$ & $\mathbf{1 0 0}$ & $\mathbf{6 0 3}(\mathbf{1 0 0})$ \\
\hline Belief in traditional & $\mathbf{m e d i c i n e}$ & & & & \\
Yes & 156 & 72.6 & 139 & 35.8 & $295(48.9)$ \\
No & 59 & 27.4 & 249 & 64.2 & $308(51.1)$ \\
Total & $\mathbf{2 1 5}$ & $\mathbf{1 0 0}$ & $\mathbf{3 8 8}$ & $\mathbf{1 0 0}$ & $\mathbf{6 0 3}(\mathbf{1 0 0})$ \\
& & & &
\end{tabular}




\begin{tabular}{|c|c|c|c|c|c|}
\hline \multicolumn{6}{|c|}{ Belief about disease causation } \\
\hline Malnutrition & 37 & 17.2 & 75 & 19.3 & $112(18.6)$ \\
\hline Witchcraft & 60 & 27.9 & 118 & 30.4 & $178(29.5)$ \\
\hline Germs & 50 & 23.3 & 105 & 27.1 & $155(25.7)$ \\
\hline I don't know & 68 & 31.6 & 90 & 23.2 & $158(26.2)$ \\
\hline Total & 215 & 100 & 388 & 100 & $603(100)$ \\
\hline \multicolumn{6}{|c|}{ Child sex preference } \\
\hline Yes & 136 & 53.9 & 218 & 62 & $354(58.7)$ \\
\hline No & 79 & 46.1 & 170 & 38 & $249(41.3)$ \\
\hline Total & 215 & 100 & 388 & 100 & $603(100)$ \\
\hline \multicolumn{6}{|c|}{ Mother's autonomy on child's health } \\
\hline Yes & 78 & 36.3 & 246 & 63.4 & $324(53.7)$ \\
\hline No & 137 & 63.7 & 142 & 36.6 & $279(46.3)$ \\
\hline Total & 215 & 100 & 388 & 100 & $603(100$ \\
\hline \multicolumn{6}{|c|}{ Family decision on child's health } \\
\hline Father & 60 & 27.9 & 151 & 38.8 & 211(34.9) \\
\hline Mother & 47 & 21.9 & 98 & 25.3 & $145(24)$ \\
\hline Both parents & 34 & 15.8 & 107 & 27.6 & $141(23.4)$ \\
\hline Grandfather & 35 & 16.3 & 17 & 4.4 & $52(8.6)$ \\
\hline Grandmother & 39 & 18.1 & 15 & 3.9 & $54(8.9)$ \\
\hline Total & 215 & 100 & 388 & 100 & $603(100)$ \\
\hline
\end{tabular}

Source: Field Survey, 2018

Women that belief in witchcraft as causes of disease experienced $27.9 \%$ under-five mortality, while respondents that belief disease is caused by malnutrition recorded the least under-five mortality (17.2\%). Table 4 further shows that the highest under-five mortality $(53.9 \%)$ was experienced by women that have preference for child sex, while $46.1 \%$ was recorded by women that do not have preference for child sex. Under-five mortality (36.3\%) was experienced by mothers that have autonomy on their child's health, while the highest underfive deaths $(63.7 \%)$ occurred among mothers that do not have autonomy on their child's health. The results of the study further indicate that $27.9 \%$ under-five mortality was experienced by mothers that husband alone decides on child's health, while mothers that said both parents take decision on child's health experienced the least under-five deaths $(15.8 \%)$.

\section{Environmental Factors Affecting Under-five Mortality}

Table 4 indicates that women that use river/stream as source of water (OR .201, P-value .002 ), uncovered well (OR .170, P- value .004) and other sources of water (OR .163, P-value .013 ) were $20 \%, 17 \%$ and $16 \%$ respectively more likely to experience under-five mortality when compared with those that use tap as source of water. In support of this finding, the use of water from poor sources such as river, stream, open well was found to be significantly associated with under-five mortality in Nigeria and Ethiopia (Akinyemi et al, 2013; Usman et al., 2016). Women that treat water (OR 0.45, P-value 021 ) were $45 \%$ less likely to experience under-five deaths, compared to mothers that do not treat water. In conformity with this finding, Oloruntoba et al. (2014) and Bitew et al., (2017) found mothers that do not treat water before use experiencing more under-five mortality in Ibadan and Ethiopia. 
Type of water storage container was found to be significantly associated with under-five mortality. The results predict $38 \%$ and 1.02 times risk of under-five mortality among women that store water in metal tank (OR .387, P-value .013) and clay pot (OR 1.02, P-value 041) respectively, relative to those that use drum/bucket/jerry can with cover. This present finding is not different from the ones carried out by Oloruntoba et al. 2014 and Tambe et al. 2015 suggesting the likelihood of diarrhea and under-five mortality among women using clay pot, rubber bucket and jerry can without cover in Ibadan and Cameroun. Table 4 further shows that women that wash water container monthly (OR 1.355, P-value .048) were 1.4 times likely to experience under-five deaths in relative to women that do that daily. Similar to this finding, infrequent washing of water storage container was also found to be associated with the risk of childhood deaths in Benin and Pakistan (Stocker and Moster, 2015; Khan and Na'az, 2018). Mothers pouring child's stool at the backyard (OR .677, P- value .034) were $68 \%$ at risk of experiencing under-five deaths in relative to mothers that flush child's stool with water. This finding is not different from that of Cronin et al, (2016) and Bawankule et $a l$, (2017) that suggested high risk of under-five deaths among women that pour child's stool on open space in India and Indonesia. The result further indicates that women disposing waste water in an open field (OR .518, P-value .008), infiltration pit (OR .367, P-value .010) and simple pit (OR .312, p- value .021) were 52\%, 37\% and 31\% respectively likely to experience under-five mortality, when compared with of women that use open drainage channels to dispose waste water. In agreement with this finding, a study carried out in Nigeria revealed that disposal of waste water in an open field was associated with diarrheal illness among under-fives (Oloruntoba et al., 2014).

Table 4: Logistic Regression Analysis of the Environmental Factors Affecting Underfive Mortality

95\% C.I for EXP (B)

\begin{tabular}{llcccc}
\hline Variables & S.E. & P-Value & OR & Lower & Upper \\
\hline Source of water & & & & & \\
Tap & RC & & & & \\
Covered well & .677 & .476 & .614 & .164 & 2.349 \\
Manual/Motorized borehole & .727 & $.013^{*}$ & .163 & .039 & .679 \\
Water vendor & .795 & .386 & .502 & .106 & 2.384 \\
River/stream & 1.241 & $.002^{*}$ & .201 & .002 & .222 \\
Uncovered well & .608 & $.004^{*}$ & .170 & .052 & .561 \\
Others & .691 & .368 & .536 & .138 & 2.07 \\
Water treatment practice & & & & & \\
Yes & $\mathrm{RC}$ & & & & \\
No & .121 & $.021^{*}$ & .451 & .471 & 12.33 \\
\hline Type of water storage container & & & & & \\
Rubber drum/bucket without cover & $\mathrm{RC}$ & & & & \\
Clay pot & .616 & .041 & 1.02 & .373 & 2.449 \\
Metal tank & .527 & .013 & .387 & .530 & .421 \\
Rubber drum/bucket/ can with cover & .944 & .101 & .421 & .517 & .333 \\
Rubber tank & .671 & .327 & .35 & .311 & .211 \\
Others & .578 & .644 & .292 & .294 & .580
\end{tabular}




\begin{tabular}{llllll}
\hline $\begin{array}{l}\text { Frequency of washing water container } \\
\text { Daily }\end{array}$ & $\mathrm{RC}$ & & & & \\
Twice a week & .596 & .947 & 1.041 & .323 & .349 \\
Weekly & .598 & .584 & 1.387 & .430 & .476 \\
Twice a month & .855 & .678 & 1.426 & .26 & .263 \\
Monthly & .574 & $.045^{*}$ & 1.355 & .241 & 7.211 \\
\hline Method of waste water disposal & & & & & \\
Open drainage channel & $\mathrm{RC}$ & & & & \\
Infiltration pit & .229 & .010 & .367 & .437 & .401 \\
Open field & .554 & $.008^{*}$ & .518 & .290 & .770 \\
Simple pit & .651 & $.021^{*}$ & .312 & 7.383 & .702 \\
Type of toilet & & & & & \\
Open pit without cover & $\mathrm{RC}$ & & & & \\
Open pit with cover & .833 & .057 & 4.879 & .952 & 24.988 \\
Water system with cover & 1.138 & .829 & .782 & .084 & 7.273 \\
Water system without cover & 774 & $.029^{*}$ & 5.418 & 1.190 & 24.68 \\
Others & .802 & $.021^{*}$ & 6.464 & 1.321 & 30.671 \\
Shared toilet & & & & & \\
No & $\mathrm{RC}$ & & & & \\
Yes & .325 & $.006^{*}$ & .555 & .232 & .893 \\
\hline Frequency of washing toilet & & & & & \\
\hline
\end{tabular}

Daily RC

Twice a week $\quad .547$

Weekly $\quad .224$

Monthly $\quad .165$

$\begin{array}{lllll}547 & .121 & .314 & .173 & 2.114\end{array}$

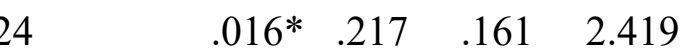

Method of child's stool disposal

Flush with water

$\begin{array}{llllll}\text { Pour at the backyard } & .677 & .034 * & .630 & .163 & 2.314\end{array}$

$\begin{array}{llllll}\text { Cover with sand } & .677 & .476 & .614 & .164 & 2.329\end{array}$

\begin{tabular}{llllll} 
Pour in a pit latrine & .565 & .558 & .718 & .238 & 2.173 \\
\hline
\end{tabular}

Method of dumping refuse

At the backyard $\quad \mathrm{RC}$

Stream/River $\quad 546$

Community refuse pit $\quad .624$

$\begin{array}{llll}.038 * & .711 & .328 & 2.233\end{array}$

Others

.432

Type of living house

Single room

Room/Parlour

Bungalow

C

Duplex

\begin{tabular}{lllll}
.680 & .832 & .866 & .228 & 3.281 \\
.833 & .057 & 4.879 & .952 & 24.988 \\
1.681 & .546 & 2.758 & .102 & 74.451 \\
1.684 & .752 & 2.194 & .084 & 95.997 \\
\hline
\end{tabular}

Story building 1.684

Type of roofing material

Stone coated sheet

Thatched roofing

Corrugated zinc sheet

Asbestos sheet

Others
$\mathrm{RC}$

.963

.863

.795

1.545

\begin{tabular}{llll}
$.023 *$ & .349 & .325 & 2.766 \\
$.044 *$ & .402 & .118 & 1.366 \\
.999 & .000 & .000 & .233 \\
\hline
\end{tabular}

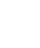




\begin{tabular}{|c|c|c|c|c|c|}
\hline \multicolumn{6}{|l|}{ Types of floor } \\
\hline \multicolumn{6}{|l|}{ Earth /mud } \\
\hline Gravel & 1.985 & .698 & .733 & .248 & 2.144 \\
\hline Cement & .512 & .792 & .873 & .320 & 2.384 \\
\hline Tiles & .691 & .368 & .536 & .138 & 2.079 \\
\hline Others & .861 & .283 & .510 & .312 & 2.484 \\
\hline \multicolumn{6}{|c|}{ No of windows per room } \\
\hline 1 & $\mathrm{RC}$ & & & & \\
\hline 2 & .683 & .828 & 1.160 & .304 & 4.419 \\
\hline 3 & .847 & .495 & 1.783 & .339 & 9.380 \\
\hline None & 1.608 & $.014^{*}$ & 1.469 & .063 & 34.324 \\
\hline \multicolumn{6}{|c|}{ Number of persons per. Room } \\
\hline $1-2$ & $\mathrm{RC}$ & & & & \\
\hline $3-4$ & .617 & .078 & 3.604 & 1.075 & 12.083 \\
\hline $5-6$ & .908 & $.032 *$ & .298 & .118 & 4.135 \\
\hline 7 above & 1.299 & $.029 *$ & 1.693 & .104 & 16.87 \\
\hline \multicolumn{6}{|c|}{ Type of cooling appliance } \\
\hline Ceiling fan & $\mathrm{RC}$ & & & & \\
\hline Table Fan & .801 & .995 & 1.005 & .209 & 4.830 \\
\hline Air conditioner & 1.784 & .527 & 3.094 & .094 & 10.998 \\
\hline None & .861 & $.003 *$ & 2.510 & 2.312 & 67.684 \\
\hline \multicolumn{6}{|c|}{ Use of mosquito net } \\
\hline Yes & $\mathrm{RC}$ & & & & \\
\hline No & .562 & $.041 *$ & .624 & .713 & 1.344 \\
\hline \multicolumn{6}{|c|}{ Type of cooking fuel } \\
\hline Electricity & $\mathrm{RC}$ & & & & \\
\hline Gas & 1.427 & .866 & .786 & .048 & 12.898 \\
\hline Kerosene & 1.402 & .059 & 2.283 & 1.364 & 33.003 \\
\hline Charcoal & 1.161 & $.007 *$ & 1.334 & .445 & 42.172 \\
\hline Wood & 1.136 & $.041 *$ & 1.471 & .175 & 15.038 \\
\hline Animal Dug & 2.042 & .927 & .829 & .015 & 45.372 \\
\hline Others & 1.250 & .403 & .352 & .030 & 4.077 \\
\hline \multicolumn{6}{|c|}{ Type of animal domesticated } \\
\hline \multicolumn{6}{|c|}{ Dog } \\
\hline Cat & .786 & .169 & 2.953 & .632 & 13.792 \\
\hline Cattle & 1.066 & .306 & 2.975 & .368 & 24.027 \\
\hline Sheep/Goat & .758 & .561 & 1.554 & .352 & 6.869 \\
\hline Birds & 1.019 & .168 & .245 & .033 & 1.806 \\
\hline None & 1.945 & .193 & .079 & .002 & 3.589 \\
\hline
\end{tabular}

* P- value $<0.05 \quad$ RC - Reference Category $\quad$ OR -Odd Ratio $\quad$ SE- Standard Error Source: Field work, 2018 
Table 4 further shows that women that use water system toilet without cover ( OR 5.418, pvalue 0.29 ) and other toilet facilities (OR 6.464, $\mathrm{P}$ - value 0.21 ) were 5.4 and 6.5 times respectively at risk of experiencing under-five deaths, when compared with those that use covered open pit toilet. Previous studies such as Mundal et al. (2009), Susuman (2016), Makate and Makate, 2016) found the use of unsafe toilet facility to be associated with underfive mortality in Kenya, Bangladesh and Zimbabwe respectively. The result of the analysis also shows that under-five mothers that share toilet facility with neighborhood (OR $0.555, \mathrm{P}-$ value .006) were $56 \%$ likely to experience under-five mortality, relative to mothers that do not share. Similar to this finding, a strong association was found between under-five mortality and shared toilet facility in Nigeria (Adeolu et al., 2016, Gbadebo et al., 2018). Mothers that wash toilet monthly (OR .711, P- value .038) and weekly (OR .217, P- value .016 ) were $71 \%$ and $23 \%$ respectively more likely to experience under-five mortality when compared with those that do that daily.

Table 4 also shows that there was no significant association between type of living house and under-five mortality. Mesike and Mojekwu (2012), Nurtor et al. (2017) did not also find any association between type of house used and under-five mortality in Nigeria and Ghana. However, Bitew (2017) found an association between dwelling houses and high odds of under-five mortality in Ethiopia. The type of floor was not significantly related to children's death. Contrary to the finding of this present study, Izugbara (2014) and Adeolu et al, (2016) found significant association between the type of floor and under-five mortality in Nigeria. Women that use thatch roof house (OR 9.567, P -value 0.00 ) were 9.5 times likely to experience child's death, relative to those that live in stone coated roof house. Previous studies have found that use of inadequate or unsafe roofing materials by households are more likely to experience under-five deaths in Nigeria and South Western Nigeria (Adebowale et al. 2017; Mesgan et al. 2017). Mothers that live in a house without window (OR 1.469, P value 0.14 ) were 1.4 times likely to experience under-five mortality when compared with those that live in a house with one window. This present finding is similar to that of Abuka (2017) where it was found that under-five mortality was associated with living house without window.

Women that sleep 7 and more in a room (OR 1.693, P - value .029) and 5-6 in a room (OR .298 , p- value .032) were 1.6 times and $30 \%$ respectively likely to experience under-five mortality when compared with women that sleep one or two in a room (Table 4). Similar to this finding, a studies in Australia and Sao Paulo suggested that children living in overcrowded room are more likely to experience respiratory problems such as coughing and asthmatic wheezing; and are also 10 times more likely to die of meningitis (Shelter, 2006; Sanders, 2007). Women that sleep under mosquito net (OR .624, P-value .041) were 62\% more likely not to experience under-five mortality, relative to those that do not sleep under mosquito net. This finding is consistent with that of Adeolu et al. (2016) and Osuorah et al, (2013) that suggested higher odds of under-five mortality among women that do not use mosquito net in Nigeria.

In this study, result further indicates that women that do not have cooling appliance (OR $2.510, \mathrm{P}$ - value. 0003 ) were 2.5 times at risk of experiencing under-five mortality, relative to mothers that use fan. Similar to this finding, Luber and MCGeehin (2008) reported that prolonged exposure to high indoor temperature can cause heat related deadly illnesses in both adult and children. Women using community refuse pit to dump refuse (OR .402, P - value 0.44 ) and stream/river ( OR .349, p-value .023) were $40 \%$ and $35 \%$ at risk of experiencing 
under-five mortality when compared with mothers that dump refuse at the backyard. In Ibadan, Nigeria, it was similarly found that women using community pit to dump refuse exposed them to high risk of diseases and under-five mortality (Oloruntoba, 2014). Mothers that use wood as cooking fuel (OR 1.471, P - value 0.41) and charcoal ( OR 1.334, p-value $.007)$ were $47 \%$ and 1.3 times at risk of experiencing under-five mortality, when compared with mothers that use electricity which is non-polluting fuel in this study. Previous studies similarly suggested more children dying of respiratory infections among mothers that use wood, animal dung and straw for cooking in Ethiopia and Tanzania (Ayemahehu et al., 2014; Susuman et al., 2016). The results of this study did not show any association between type of animal domesticated and under-five deaths. Similar result was reported by Oloruntoba (2014), suggesting that domestication of animals was not significantly related to under-five mortality in Nigeria.

\section{Cultural Factors Affecting Under-five Mortality}

In Table 5, mothers that belief in traditional medicine (OR .095, p - value .000) were 95\% likely to experience under-five mortality, compared to those that do not belief in traditional medicine. Similar to this finding, women in Southwestern Nigeria and New Guinea's belief in traditional treatment of "Abiku" children (non-responsive to modern medicine) was found to be associated with child's health status (Fayisetan et al, 1997; Ogunjuyigbe 2004; Macfarlane, 2005). Mothers that do not have knowledge about what causes disease (OR 2.41, p- value 0.11 ) were 2.4 times at risk of experiencing under-five mortality, relative to women that belief malnutrition is the cause of disease. This result is supported by the work of Ashorn (2003) and Archibong et al. (2017) that found mothers associating the death of their children to witchcraft in Malawi and Calabar, Nigeria.

Table 5: Logistic Regression Analysis of the Cultural Factors Affecting Under-five Mortality

\begin{tabular}{llllll}
\hline Ethnicity & S.E. & P-Value & OR & Lower & Upper \\
\hline Dakarikari & RC & & & & \\
Hausa & .555 & $.017^{*}$ & .621 & .014 & .395 \\
Igbo & 1.465 & .213 & .231 & .411 & 2.111 \\
Yoruba & .531 & .102 & .220 & .337 & 2.321 \\
Kambari & 1.012 & .133 & .121 & .228 & 1.223 \\
Fulfude & 1.771 & .211 & .333 & .677 & 4.361 \\
Others & 1.350 & .303 & .425 & .5276 & 3.554 \\
\hline Practice of food taboo & & & & & \\
No & RC & & & & \\
Yes & .238 & $.022^{*}$ & .471 & .077 & .913 \\
Total & & & & & \\
\hline Belief in traditional medicine & & & & & \\
No & RC & & & & \\
Yes & .275 & $.000^{*}$ & .095 & 2.737 & 8.033
\end{tabular}




\begin{tabular}{llllll}
\hline Belief about disease causation & & & & & \\
Witchcraft & $\mathrm{RC}$ & & & & \\
Malnutrition & .340 & $000^{*}$ & .155 & .080 & .302 \\
Germs & .329 & .058 & 3.981 & 2.091 & 7.581 \\
I don't know & .347 & $.011^{*}$ & 2.410 & 1.221 & 4.757 \\
\hline $\begin{array}{l}\text { Child's sex preference } \\
\text { Yes }\end{array}$ & $\mathrm{RC}$ & & & & \\
No & .240 & .140 & .101 & .063 & .161 \\
\hline Mother's Autonomy on child's health & & & & \\
Yes & $\mathrm{RC}$ & & & & \\
& .231 & $.042 *$ & .652 & .833 & 6.317 \\
No & & & & & \\
\hline Family decision on child's health & & & & & \\
Both parents & $\mathrm{RC}$ & & & & \\
Mother & .639 & .349 & .550 & .157 & 1.922 \\
Father & 1.300 & $.033 *$ & .063 & .005 & .800 \\
Grandmother & 1.250 & .403 & .352 & .030 & 4.077 \\
Grandfather & .307 & $.006 *$ & 2.399 & 1.276 & 4.251 \\
\hline
\end{tabular}

* P- value $<0.05 \quad$ RC - Reference Category $\quad$ OR -Odd Ratio $\quad$ SE- Standard Error

Source: Field work, 2018

The result in Table 5 further showed that home where grandfather take child's health decision (OR .307, P - value .006) is likely to experience 2.3 times under-five mortality, relative to home where both parents take child's health decision. This finding confirmed the work of Ashorn (2003) where it was reported that in majority of African societies, a man takes major decision on major matters, including child's health with both parents taken decision in rare cases; which has negative health implications on the child. Mothers from Hausa ethnic group (OR .621, P-value .017) were likely to experience $62 \%$ under-five mortality, relative to Dakarkari ethnic group. In support of this finding, previous studies have shown significant differentials between ethnic groups in the odds of dying before the age of 5 years; suggesting under-five mortality to be higher among Hausa, Fulani and Kanuri ethnic groups in Nigeria (Antai, 2010; Antai, 2011; Arigbede, 2012; Adedini, 2013 and Mundi et al., 2019).

Table 5 further indicates that mothers that practice Islamic religion (OR .414, P-value .021) were $41 \%$ more likely to experience under-five mortality than mothers in Catholic faith. Consistent with this finding, Bhalotra et al (2013), Yaya et al. (2017) and Mundi et al. (2019) also found women belonging to Islamic faith to be associated with under-five mortality in Nigeria, India and Adamawa state, Nigeria.

The result also showed that mothers who practice food taboo (OR .471, P-value .022) were $47 \%$ likely to experience under-five mortality, relative to those that do not practice food taboo. In support of this finding, Sanghvi et al. (2001) found under-five at risk of dying due to their mothers' belief in food taboo in India. Mother's autonomy on child's health (OR .652 , P-value .043) was associated with under-five mortality in the study area. The result shows that $65 \%$ of the children are at risk of death among women with no autonomy on 
child's health matters, relative to those that have. In agreement with this finding, Fantahu et al (2007) and Khan et al (2018) predicted likely occurrence of under-five mortality in Ethiopia and Pakistan due to low decision-making power of women in respect of their children's health

\section{CONCLUSION AND RECOMMENDATION}

The main purpose of this study was to determine environmental and cultural factors affecting under-five mortality in Kebbi state. Despite the efforts of the government to reduce underfive mortality, it is still high in Kebbi state. The results of the Logistic regression analysis revealed that source of water, frequency of washing water container, water treatment, method of disposing waste water, type of toilet, shared toilet, frequency of washing toilet, method of disposing child's stool, type of cooling appliance, number of persons per room, use of mosquito net, refuse disposal method and type of cooking fuel were found to be environmental factors significantly affecting under-five mortality; while ethnicity, religion, practice of food taboo, belief in traditional medicine, belief about disease causation, mother's autonomy on child's health and family's decision on child's health were found to be cultural factors significantly affecting under-five mortality in Kebbi state. In conclusion, environmental and cultural factors affect under-five mortality in Kebbi state. Therefore, it was recommended that to reduce under-five mortality rate government at all levels should step up efforts in providing adequate infrastructure such as potable sources of water, sanitary facilities, water drainage system and safe refuse disposal system for public use. Government at all levels, and cultural organizations should scale up advocacy programmes aimed at improving women participation in child's health decision-making in the society. Also, women and their spouses should be educated on some cultural beliefs that have negative effects on child's health.

\section{Ethical considerations}

All respondents consented to participate in this study. Also, ethical clearance from the Ethics Research Committee of Kebbi State Ministry of Health was sought and granted.

\section{Acknowledgment}

Authors wish to acknowledge the financial support received from the Tertiary Education Trust Fund (TETFund); which facilitated the conduct of this study.

\section{REFERENCES}

Abuka T. (2017) Prevalence of Pneumonia and Associated Factors Among Children, 2 -59 months old in Wondo-Genet district, Sidama zone, Ethiopia. Current Pediatrics Research. 21(1), Pp. 19 - 25. Available at:www.currentpediatrics. com

Adebowale, S.A; Morakinyo, O.M and Ana G.R. (2017) Housing Materials as predictors of under-five mortality in Nigeria: Evidence from 2013 Demographic and Health Survey.BMC Pediatrics, 17(30), Pp. $1-13$ 
Adedini, S.A (2013) Contextual Determinants of Infant and Child Mortality in Nigeria. Unpublished Doctoral Thesis Submitted to the Faculty of Humanities, University of the Witwatersrand, Johannesburg, South Africa

Adeolu, M.O., Akpa, O.M; Adeolu, A.T and Aladeniyi, I.O. (2016) Environmental and Socioeconomic Determinants of Child Mortality: Evidence from the 2013 Nigeria Demographic and Health Survey. America Journal of Public Health Research.; vol. 4, No. 4. Available at: http://pubs.sciepub.com/ajphr/4/4/3.

Akinyemi J.O, Bangboye E.A and Ayeni, O. (2013) New trends in under-five mortality determinants and their effect on child survival in Nigeria. A review of childhood mortality data from 1990-2008. African population studies. Vol. 27 (1). Pp. 25-42. Available at: http:llaps.journals.ac.za.

Antai, D (2010) Social Context, Social position and Child survival: Social Determinants of Child Health Inequalities in Nigeria. Department of Environmental Medicine, Karohinska Institute, Stockholm, Sweden.

Antai, D (2011) Inequalities in Under-five Mortality in Nigeria. Do Ethnicity and Socioeconomic Position Matter? Journal of Epidemiology 21(1), Pp. 13-20

Archibong, E.P; Enang, E.E and Bassey, G.E (2017) Witchcraft Beliefs in Diseases Causation and Health-Seeking behavior in Pregnancy of Women in Calabar, Southern Nigeria. Journal of Humanities and Social Science Vol. 22, Issue 6, Ver. 4, PP. 24 - 28

Arigbede, Y.A (2012) Childhood Diseases mapping in Kaduna State using Geographic Information Systems. Unpublished Thesis of Master of Science, Department of Geography, Ahmadu Bello University, Zaria.

Ashorn, U (2003) Child Health-Seeking Behavoiur in Lungwena, Malawi. Unpublished Academic Dissertation, Faculty of Medicine, University of Tempere, Finland. Available at: http://granum.ut.fi

Ayemayehu, M; Alemu, K; Sharma, H.R; Gizaw, Z and Shibru, A (2014) Households Fuel use and Acute Respiratory Infections in Children Under-five years of Age in Gondar City of Ethiopia. Journal of Environment and earth Sciences. Vol. 4, No. 7. Available at: www.wiste.or

Ayotunde, T. Mary, O; Melvin A.O and Faniyi, F.F. (2009) Maternal Age at Birth and Under-five Mortality in Nigeria. East African Journal of public Health. Volume 6, number 1, Pp. 1-10.

Bawankule, R; Singh, A; Kumar, K and Pedgaonkar, K. (2017) Disposal of children's stools and its association with childhood diarrhea in India. BMC public Health.; 17(12), Pp. 1 - 9.

Bhalotra, S (2010) Religion and Child Death in India. Full Research Report, ESRC End of Award Report, Sweden

Bitew, B.D; Wouldu, W and Gizaw, Z (2017) Childhood Diarrhea Morbidity and Sanitation Predictors in Nomadic Community. Italian Journal of Pediatrics, 43(91), PP. 2 - 8

Cronin, A.A; Sebayang, S.K; Torlesse, H and Nandy, R. (2015) Association of safe disposal of child feaces and reported diarrhea in Indonesia: Need for stronger focus on neglected risk. International Journal of environmental Research and Public Health.13(310), Pp. 1-13 available at: www.mdpi.com/journal

Edeme, R.K; Ifelunini, I.A and Obinna, O.S (2015) Relationship between household income and child mortality in Nigeria.America Journal of life sciences 2(6-4). Available at:htt://wwwsciencepublishinggroup. Com/j/ajls

Fasina, F.F. (2015) Household Sanitation and Child Morbidity. Convenant International Journal of Psychology. Vol. 1. No. 1, Pp. 35 - 49. Available at http://www.researchgate.net/publication

Fantahu, M; Berhane, Y; wall, S; Byass, P and Hogberg, U (2007) Women's involvement in household decision-making and strengthening social capital-crucial factors for child survival in Ethiopia. 9, Pp. $583-589$ 
Feyisetan, B.J; Asa, S and Ebigbola, A (1997) Mothers' Management of Childhood diseases in Yorubaland: The influence of cultural beliefs. Health Transition Review 7, Pp. 221234

Gbadebo, B.M; Fagbamigbe, A.F and Adebowale, S.A. (2018) Environmental Factors as Predictors of Childhood Mortality Experience in Nigeria. Africa Journal of Environmental Health Sciences. Vol. 5, Pp. 23-34.

Isreal, G.D. (1992) Determining Sample Size. IFAS Extension. University of Florida. Pp. 1-5, available at:www.tarleton.edu $>$ documents $>$ sa

Izugbara, C (2014) Whose child is dying? Household characteristics and under-five mortality in Nigeria.SAJCH, Volume 8, No 1.

Jacob, B.A; Ludwig, J and Millero, D.L. (2011)The effects of housing and neighborhood conditions on child mortality. Working Paper 17369. National Bureau of Economic Research. Available at:http://www.nber.org/papers/w1736

Kandara, N.B; Chenji, N.S, Saverio, S and Cappuccio, F.P (2007) Spatial Analysis of Risk Factors for Childhood Mortality in Nigeria. American Society of Tropical Medicine and Hygiene, 77 (4).Pp. 770-778.

Khan, M.I and Naaz, S. (2018) The Role of Water and Hygiene Project of Integrated Regional Support Programme (IRSP) in District Swabi, KhyberPAkhTunkhwa. Sociology International Journal. Vol. 2, Issue 4, Pp. $327-333$.

Khan, R. E. A; Bari, K. M and Raza, M. A (2018) Socio-economic determinants of child mortality: Evidence from Pakistan Demographic and Health Survey. Business Review. Paper No. 93839. Available at: https://mpra.ub.uni-muenchende/93839

Luber, G and MCgeehin, M. (2008) Climate Change and Extreme Heat Events. America Journal of Preventive Medicine. 35(5), PP. 429 - 435.

Macfarlane, J (2005) The Relationship Between Cultural Reliefs and Treatment-Seeking Behaviour in Papau New Guinea; Implications for the Incorporation of Traditional Medicine into the Health System. Unpublished Thesis for the Award of Doctor of International Health, Curtin University of Technology. Centre for International Health.

Makate, M and Makate, C. (2016) Poor Sanitation and Child Mortality Outcomes in Zimbabwe. Munich Personal Archive. Paper No. 7283/.Available at:https://mpra.ub.unimuechen.de

Mesgan, P.E and Adeniji - IIori, O.M. (2017) Household environmental factors and childhood mortality in South Western Nigeria. Springer link. Available at:link.springer.com

Mesike, C.G and Mojekwu, J.W. (2012) Environmental Determinants of Child Mortality in Nigeria. Journal of Sustainable Development, vol. 5, No.1, pp. 65-75. Available at:www.ccsenet.org/jsd.

Mosley, W.H and Chen, L.C(1970). An Analytical Framework for the Study of Child Survival in Developing Countries. Population Council.; available at: http://www.jstor.org/ stable/280795

Mundal, N.I Hussain, K and Ali, K. (2009) Factors Influencing Infant and Child Mortality: A Case Study of Rajshahi District, Bangladesh. Journal of Human Ecology. 2(16), Pp. 8-12.

Mundi, R; Nwankwo, B.B; Dakyes, S.P; Ishaya, S and Yohanna, S. (2019) Demographic and Socio-Economic Factors Associated with Under-five Mortality in Nigerian's Federal Capital Territory. Journal of Social Sciences and Humanities. 2(2) Pp. 43 - 50.

Mundi, R; Nwankwo, B.B; Dakyes, S.P; Ishaya, S andYohanna, S. (2019) Demographic and Socio-Economic Factors Associated with Under-five Mortality in Adamawa State of Nigeria. International Journal of Research and Innovation in Social Science. Volume III, Issue IV, pp $73-80$.

National Bureau of Statistics and United Nations Children's Fund (2017) Multiple Indicator Cluster Survey (2016-2017) Survey finding Report, Abuja-Nigeria. NBS and UNICEF. 
National Population Commission and ICF International (2019) Nigeria Demographic and Health Survey. NPC and ICF International.

Nutor, J.H; Bell, J.F; Slaughter-Acey, J.C; Joseph, J.G; Apesoavarano, E.C and Siantz, M.L (2017) Household resources as determinants of child mortality in Ghana. Rural and Remote Health. Vol. 17, Issue 4. Pp. 1-12. Available at: www.rrh.org.au

Ogunjuyigbe, P.O (2004) Under-five Mortality in Nigeria: Perception and Attitudes of the Yorubas towards the Existence of"Abiku". Demographic Research, Pp.43-56. Available at: www.demographic-research.org/volimes/vol.11/2/

Oloruntoba, E.O; Folarin, T.B; Ayede, A.I. (2014) Hygiene and sanitation risk factors of diarrhoeal disease in Ibadan, Nigeria. African Health Sciences. Vol. 14, Issue 4. Pp.1001 1011.

Osuorah, D.C; Ezendu, C.E, Onah, S.K and Anyabow, O.T. (2013) Household bed net ownership and use among under-five children in Nigeria. Research and Report in Tropical Medicine. Vol. 4, Pp. $15-27$

Sanders, D; Reyonolds, L; Eley, B; Kroon, M; Zar, H; Davies, M; Westwood, T; Nongena, P and Van Heerden, T. (2007) Western Cape Burden of Diseases Reduction project: Decreasing the burden of childhood disease. University of the Western Cape, South Africa.

Sanghvi, U; Thankappan, K.R; Sarma, P.S and Sali, N (2001) Assessing Potential Risk Factors for Child Malnutrition. Tropical Pediatrics, Vol. 47, Pp. 350 - 355

Sarmah, H.K; Hazarika, B.B and Choudhury, G. (2013) An Investigation on Effect of Bias on Determination of Sample Size on the Basis of Data Related to Schools of Guwahati. International Journal of Applied Mathematics and Statistical Sciences. Vol. 2, Issue 1. Pp. $34-48$

Shelter (2006). Chance of a Life: The impact of bad housing on children's lives. Pp. 23-24

Stocker, A and Mosler, H.J. (2015) Contextual and socio psychological factors in predicting habitual cleaning of water storage container in rural Benin. Water Resources Research. 51, Pp. $2000-2008$

Susuman, A.S. (2012) Child Mortality Rate in Ethiopia. An Iranian Journal of public Health.; 14(3), Pp.9-19. Available at:htts://www.researchgate.net/publication/ 232742890

Tambe, A.B; Nzefa, L.D and Nicoline, N.A (2015) Childhood Diarrhea Determinants in SubSaharan African: A cross sectional study of Tiko-Cameroon. Challenge open access. No.6

United Nations (2013) End Poverty: Millennium Development Goals and Beyond 2015. Fact sheet. Available at: www.un.org/milleniumgoals

United Nations (2015) Millennium Development Goals Report, 2015: Time for the Global Action. Available at: www.un.org $>$ pdf $>$ backgrounders

United Nations Development Programme and United Nations Research Institute for Social Development (2017) Global Trends: Challenges and Opportunities in the Sustainable Development Goals. Available at: www.undp.org

Usman, M.A; Gerber, N and Joachim, V. (2016) The Impact of Drinking Water Quality and Sanitation on Child Health: Evidence from rural Ethiopia, ZEP. Discussion Papers on Development Policy.

World Health Organization (2019) More Women and Children Survive Today More than Ever Before: United Nations Report.. https://www.who.inter/news-room

World Health Organization (2019) Children: Reducing Child Mortality: Fact Sheet.. https//who.int/news-room/factsheets: www.mdpi.com/journal/challenges

Yaya, S; Tudeme, G; Bishwajit, G and Kadio, B (2017) Prevalence and determinants of childhood mortality in Nigeria. BMC public health, 17:485, Pp. $1-7$

Yuldiz, S; Toruner, E.K and Altay, N (2018) Effects of Different Cultures on Child Health. Journal of Nursing Practitioners, 2(2), PP. $6-10$ 